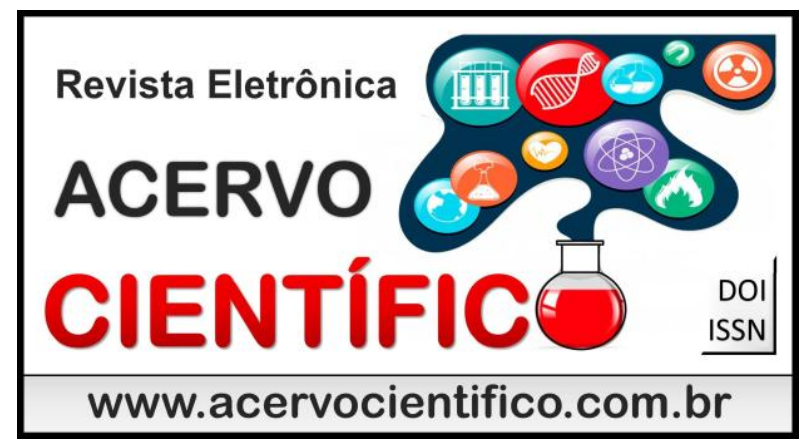

REVISÃO

Recebido em: 6/2019

Aceito em: 7/2019

Publicado em: 8/2019

\title{
Urbanização e segregação na cidade contemporânea: uma revisão bibliográfica
}

\begin{abstract}
Urbanization and Segregation in Contemporary City: a bibliographic review
Urbanización y Segregación en la Ciudad Contemporánea: una revisión bibliográfica

Katia Luzia Silveira Silva Vieira ${ }^{1 *}$.

Resumo: Este artigo tem como objetivo desenvolver uma reflexão teórica sobre o processo de urbanização e segregação socioespacial. Em função da complexidade histórica e teórica, os constantes debates sobre segregação socioespacial que ocorrem na sociedade trazem à tona os contrassensos inerentes ao processo de urbanização das cidades. Este processo está intimamente ligado à aceleração da industrialização em ambos trazem consequências à qualidade de vida da população, nos mais variados aspectos. O processo de urbanização, resultado de uma concentração de massa urbana, intensificou as disputas pelo espaço urbano, fomentando as desigualdades sociais, agravadas pelas inadequadas condições de acesso aos meios de consumo coletivo.
\end{abstract}

Palavras-chave: Segregação, Urbanização, Cidade Contemporânea.

\begin{abstract}
This article aims to develop a theoretical reflection on theprocess of urbanization and sociospatial segregation. Dueto the historical and theoretical complexity, the constantdebates about sociospatial segrega tion that occur in societybring to the fore the counterfunctions inherent to theurbanization process of cities. T his process is intimatelylinked to the acceleration of industrialization in both bringconsequences to the quality of life of the population, invarious aspects. The urbanization process, the result of aconcentration of urban $\mathrm{m}$ ass, intensified the disputes in theurban space, fostering social inequalities, aggravated byinadequate conditi ons of access to the means of collectiveconsumption.
\end{abstract}

Keywords: Segregation, Urbanization, Contemporary City.

Resumen: Este artículo tiene como objetivo desarrollar una reflexión teórica sobre el proceso de urbanización y segregación socioespacial. Debido a la complejidad histórica y teórica, los constantes debates sobre la segregación socioespacial que se producen en la sociedad antepone a las contrafunciones inherentes al proceso de urbanización de las ciudades. Este proceso está íntimamente ligado a la aceleración de la industrialización en ambos traer consecuencias a la calidad de vida de la población, en diversos aspectos. El proceso de urbanización, fruto de una concentración de masa urbana, intensificó las disputas en el espacio urbano, fomentando las desigualdades sociales, agravadas por condiciones inadecuadas de acceso a los medios de consumo colectivo.

Palabras clave: Segregación, Urbanización, Ciudad Contemporánea.

1Universidade Federal de Uberlândia (UFU), Ituiutaba - MG. *E-mail: katialuzia@ufu.br 


\section{INTRODUÇÃO}

A raiz da urbanização brasileira está ligada à expansão da cultura do café e do crescimento industrial. A substituição do escravo pelo trabalhador livre, o aperfeiçoamento do sistema de transporte, substituindo o transporte em lombo de burro e carro de bois pelas ferrovias, a generalização do uso do navio a vapor, na segunda metade do século XIX, coincidem com a demanda crescente de café pelo mercado internacional, acarretando uma espacialização crescente de produção cafeeira. A industrialização passa a ter seus efeitos mais profundos a partir do século XX, com a expansão comercial e integração ao mercado internacional. $A$ partir do momento que as pessoas deixavam o campo e migravam para a cidade, houve uma tendência para melhoramentos urbanos: sistema de calçamento, iluminação, abastecimento de água, transporte público (COSTA EV, 1994).

Para Maricato E (2010), a indústria nascente aos poucos se expande e as cidades deixam de ser somente o local das atividades administrativas, comerciais, financeiras e culturais, e começa a ser o local de produção. Os imigrantes que não foram para o campo, escravo libertos e trabalhadores livres passaram a constituir uma nova massa urbana, que tinha demanda de produtos industrializados. Essa crescente massa urbana intensificou uma demanda por habitação, transportes e demais serviços públicos urbanos até então inéditos.

Como a população urbana crescia rapidamente, na mesma proporção surgiam problemas de ordem pública e sanitária, pois a nova massa urbana estava desprovidas de infraestrutura e qualidade de vida, com intensa demanda por habitação, transportes e demais serviços públicos urbanos, o que propiciou ao Estado, utilizando um movimento ideológico de sanitarismo e higienização da cidade, a brecha para cumprir seu papel para manter a saúde pública e consequentemente preservar da degradação o território das classes mais endinheiradas, visando a manutenção do valor da terra. Assim entre o final do século XIX e início do século XX, reformas urbanas foram idealizadas e obras de saneamento realizadas, com base em um urbanismo moderno, que tinha o intuito de eliminar a endemias e embelezar a cidade, buscando assim elevar o mercado imobiliário capitalista (MARICATO E, et al, 2002).

Neste processo, a população mais pobre era expulsa para os morros, áreas periféricas e encostas de forma desordenada, tornando-se excluídos pela falta de investimentos e de infraestrutura necessários para abrigar essa parte da população com qualidade de vida nessas áreas renegadas. Como consequência dessa crescente aglomeração de população urbana, de um lado são produzidas áreas urbanas supervalorizadas, e do outro, sobram os espaços menos valorizados, sendo estes destinados à parte da população com menor poder aquisitivo, em que os investimentos públicos e privado não condizem com a real necessidades da população, especialmente no que tange à infraestrutura e serviços coletivos, gerando o elemento da segregação socioespacial (VILAÇA F, 2001).

Inaugura-se assim o urbanismo que iria se consolidar durante todo século XX no Brasil: a modernização excludente, ou seja, o investimento nas áreas que constituem o cenário da cidade hegemônica ou oficial, com a consequente segregação e diferenciação acentuada na ocupação e na distribuição dos equipamentos urbanos. "Se na cidade imperial os escravos viviam juntos a seus proprietários, a cidade de República separa o trabalho do ócio. Expulsa os negros e brancos pobres para as periferias, para os subúrbios, para os morros ou para as várzeas" (MARICATO E, 2010).

Na obra intitulada Metrópole Corporativa Fragmentada, Milton Santos, descreve sobre a oposição entre a cidade visível e invisível, fazendo alusão às diferenças de infraestrutura entre o centro e a periferia. Ao analisar os motivos desse contraste, Santos M (2009) afirma que a explicação deve ser encontrada na decisão política de satisfazer a certas camadas de população em detrimento a outras, mesmo quando estão em jogo serviços essenciais. Na cidade capitalista, o acesso desigual é muitas vezes restrito à classe social a qual o indivíduo pertence, o que gera uma desarticulação socioespacial e uma disputa desigual pelos acessos, separando cada vez mais os ricos dos pobres.

O objetivo do estudo foi realizar uma reflexão teórica, por meio de revisão bibliográfica, sobre o processo de urbanização e segregação socioespacial. Os constantes debates sobre a urbanização, em seu 
gigantesco movimento de construção das cidades, trazem à tona os contrassensos inerentes ao surgimento dos problemas para assentamento, manutenção e qualidade de vida da população, nos mais variados aspectos.

\section{MÉTODOS}

Este estudo tem como característica a revisão, mediante o levantamento bibliográfico, para possibilitar a organização histórica e teórica da pesquisa sobre o processo de urbanização no Brasil. Esse levantamento será realizado em materiais bibliográficos que possibilitarão a construção da pesquisa, dentre eles livros, teses, dissertações, artigos e todo material que verse sobre o tema da investigação, sejam estudos teóricos ou empíricos, e seus desfechos no tocante a segregação socioespacial. Desta forma, a pesquisa foi estruturada na questão temática, mas não esgotam o acervo bibliográfico dos temas relacionados, além de ser importante salientar que outras leituras e anotações sobre temas conexos foram realizadas para agregar o conhecimento teórico.

\section{RESULTADOS E DISCUSSÃO}

A partir da segunda metade do século XX, o processo de urbanização no Brasil apresenta-se intenso. Segundo Maricato E (2001), em 1940, 18,8 milhões de pessoas residiam nas áreas urbanas, o que em 2000 era de aproximadamente 138 milhões de pessoas. Ao trazer esses números para o último censo realizado pelo IBGE, em 2010, 160 milhões de pessoas moravam nas cidades. Observa-se um histórico crescimento desordenado das cidades.

Caracterizado pela dispersão urbana, o crescimento desordenado das cidades trouxe com consequência, além da segregação socioespacial, problemas de mobilidade urbana que foram acentuados devido à ausência de políticas púbicas efetivas. A segregação socioespacial é integrante e fundamental na produção do espaço urbano. Sua temática, apesar de ser tratada em várias perspectivas, está longe de ser esgotada, uma vez que a relação da sociedade com o espaço é mutável e também, levando-se em consideração os processos decorrentes da urbanização (MARICATO E, 2013).

Ao buscar a significado da palavra segregar, o dicionário Aurélio (2004) define: a) pôr à margem, marginalizar e b) afastar-se, isolar-se. Assim, o ato se segregar está relacionado com exclusão, como quem está à margem da sociedade. Segundo Vasconcelos PA, et al. (2013), "o conceito de segregação é um dos mais discutidos na literatura das ciências sociais. Sua origem histórica teria se dado na transformação do gueto de Veneza, com a reclusão dos judeus numa ilhota, com muros e portas".

O conceito de segregação socioespacial não é simples, e seu entendimento deve levar em consideração sua complexidade nas mais variadas perspectivas. Para Sposito MEB (2013), a segregação é um conceito polissêmico, por isso, corre perigo de perder força explicativa. Ele merece, ser tratado com cuidado teórico e deve ser adotado com vistas a se alcançar a precisão, à luz da realidade urbana latino-americana". Como pode estar ligado às relações com o outro e com a realidade em que é aplicada, seu conceito é importante para compreender a realidade urbana contemporânea. Complementando, Spósito MEB (2013) conceitua que "segregação seria sinônimo ou expressão de qualquer forma de diferenciação ou desigualdade nas cidades".

Segundo Ana Fani Alessandri Carlos (2013), a segregação vivida no cotidiano é apresentada como diferença, tanto nas formas de acesso à moradia como em relação às condições de transporte para acesso às atividades urbanas, bem como na deterioração, cerceamento e diminuição dos espaços públicos, deixando claro que a ótica do capitalismo, em que há uma mercantilização do espaço urbano, é que produz a segregação no processo de reprodução social. A autora coloca a cidade como produto, produzido pelo sistema capitalista, gerando a cidade mercadoria e dando todas as condições propícias para que o espaço urbano com status de mercadoria seja controlado pelo mercado imobiliário. 
Considerando que o espaço geográfico é um produto histórico e social, sendo necessário para as práticas e relações socioespaciais, envolvendo assim as condições de uso e apropriação, a segregação socioespacial seria inerente a construção do espaço urbano capitalista, onde as desigualdades sociespaciais aparecem na paisagem urbana em função dos diferentes níveis de circulação do capital, em que, de forma concomitante, o espaço é socialmente produzido, sua apropriação é particular e seu uso está condicionado à troca. "Assim a segregação urbana se expressa, por exemplo na morfologia profundamente desigual das habitações, na dificuldade e ou impossibilidade de acesso à centralidade urbana e aos serviços." (CARLOS AFA, 2013).

Villaça $F$ (2001) destaca que há segregações das mais variadas naturezas, mas abordando a segregação das classes sociais, entende que é um processo que ocorre quando diferentes camadas ou classes sociais se concentram em diferentes regiões da metrópole. $O$ autor infere que uma concentração de classes no espaço urbano não impede a presença ou o crescimento de classes distintas no mesmo espaço, destacando que não há em nenhuma metrópole brasileira a presença exclusiva de indivíduos das camadas de mais alta renda concentrada em uma região, porém existe a exclusividade de camadas de baixa renda em grandes regiões urbanas.

Nas metrópoles brasileiras, o padrão de segregação mais conhecido é o centro versus periferia, em que o primeiro é ocupado pelos indivíduos de mais alta renda, com acesso a maioria dos serviços urbanos, tanto públicos como privados. Já a periferia, predominantemente ocupada pelos indivíduos das camadas de baixa renda, é subequipada de serviços públicos e de infraestrutura. (VILLAÇA F, 2001)

Para Villaça $F$ (2001), a distribuição das residências no espaço produz sua diferenciação social e há uma estratificação urbana correspondente a um sistema de estratificação social. No caso em que a distância social tem forte expressão espacial, ocorre a segregação urbana. Essa diferenciação social faz com que alguns grupos de pessoas sem unam, e outros se separam. Os mais ricos, se segregam em condomínios. Os mais pobres, se segregam na periferia, favelas, morros e encostas.

O processo de urbanização começou a se consolidar impulsionado pelo trabalhador livre, pela proclamação da República e pelo desenrolar da indústria. Como o Brasil foi o país que permaneceu com o tempo mais prolongado de escravidão na era moderna, o processo de industrialização iniciou-se de forma tardia, e induzido em grande parte pelo Estado, que por meio de mecanismos distintos, favoreceu a iniciativa privada para conseguir assegurar o desenvolvimento industrial no país (COSTA EV, 1994).

Esse incentivo à industrialização, propiciado pelo Estado, promove a difusão da ideologia de ascensão social, o que fez com que a classe trabalhadora fosse atraída da área rural para os centros urbanos, com vista na melhoria das condições de vida. Os imigrantes que não foram para o campo, escravo libertos e trabalhadores livres passaram a constituir uma nova massa urbana.

Porém, as características do sistema capitalista excludente tornaram-se ainda mais acentuadas com a migração dessa massa urbana. Esse grande movimento de construção das cidades trouxe a necessidade de adequação para assentamento residencial e atendimento das necessidades básicas da população.

Essa crescente massa urbana intensificou uma demanda por suas necessidades de trabalho, habitação, saúde, água, energia, transportes e demais serviços públicos urbanos coletivos (MARICATO E, 2001).

Para Maricato E (2001), a produção e apropriação do espaço urbano não só reflete as desigualdades e as contradições sociais, como também as reafirma e as produz. Ao privilegiar uma parte em detrimento a outra, fomentada pela especulação imobiliária, áreas formais e informais surgem no espaço urbano, segregando e sendo segregadas.

Segundo Villaça $F$ (2001), "a segregação é uma manifestação da renda fundiária urbana, fenômeno produzido pelos mecanismos de formação dos preços do solo, estes, por sua vez, determinados (...) pela nova divisão social e espacial do trabalho". Os que pertencem às classes de mais alta renda se tornam detentores das áreas mais caras, e os de baixa renda, ficam com as áreas menos valorizadas do espaço urbano. 
De acordo com Boareto $R$ (2008), os problemas enfrentados diariamente pelas pessoas que se locomoverem nas cidades em gerem são analisados de forma fragmentada, dissociando o sistema de transporte público, a circulação de veículos particulares e o uso do solo. A análise dos sistemas de transporte tende a se focada nos aspectos de sua operação, na garantia da fluidez de veículos, na expansão do sistema viário e na segurança. $O$ uso e a ocupação do solo são predominantemente analisados dentro de uma relação de mercado.

O processo de urbanização trouxe à tona o conflito de populações de diversos níveis de renda versus a apropriação e uso do solo. Houve a fragmentação do espaço, onde os bairros periféricos ficam cada vez mais distantes dos locais de lazer, trabalho e do centro comercial, e em geral, a população mais carente é a mais afetada. Assim, houve a necessidade da elaboração de diretrizes para o desenvolvimento urbano, e que inserissem a mobilidade urbana como um indicador de qualidade de vida (VILAÇA F, 2001).

\section{CONSIDERAÇÕES FINAIS}

Em função da complexidade histórica e teórica, os constantes debates sobre segregação socioespacial que ocorrem na sociedade trazem à tona os contrassensos inerentes ao processo de urbanização das cidades. Este processo está intimamente ligado à aceleração da industrialização em ambos trazem consequências à qualidade de vida da população, nos mais variados aspectos. Como resultado da crescente massa urbana, dois movimentos contraditórios surgem: de um lado, espaços urbanos são produzidos e supervalorizados, atraindo investimentos de caráter privado, atraindo a camada de mais alta renda para a construção de luxuosas residências. Do outro, os indivíduos de menor poder aquisitivo se deslocam para espaços menos valorizados, local onde os investimentos públicos e privados não correspondem a real necessidade dessas populações, gerando a segregação socioespacial. Os diversos contornos da reprodução social imprimem novas formas de configuração da segregação. Na atualidade, a precariedade nas condições de trabalho, infraestrutura, transportes, saneamento e moradia, principalmente da camada mais pobres da população, aprofunda as manifestações de violência, insegurança e baixa qualidade de vida, além da precarização das relações de trabalho e consequente agravamento das desigualdades sociais.

\section{REFERÊNCIAS}

1. BOARETO R. A política de mobilidade urbana e a construção de cidades sustentáveis. Ciência e Ambiente, 2008. (37):73-92

2. CARLOS AFA. A prática espacial urbana como segregação e "o direito a cidade" como horizonte utópico. In: VASCONCELOS PA, CORRÊA RL, PINTAUDI SM. (Org.). A cidade contemporânea: segregação espacial. São Paulo: Contexto, 2013.

3. COSTA EV. Da monarquia à república: Momentos Decisivos. 6. ed. São Paulo: Brasiliense, 1994.

4. FERREIRA ABH. Mini Aurélio. O dicionário da língua portuguesa. 6.ed. Curitiba: Posigraf, 2004.

5. INSTITUTO BRASILEIRO DE GEOGRAFIA E ESTATíSTICA. Censo Demográfico 2010. Rio de Janeiro: IBGE, 2010.

6. MARICATO E, ARANTES O, VAINER C. A cidade do pensamento único: desmanchando consensos. Editora Vozes 2002.

7. MARICATO E. Brasil, cidades: alternativas para a crise urbana. 2.ed. Petrópolis: Vozes, 2001.

8. MARICATO E. Cidades Rebeldes: Passe livre e as manifestações que tomaram as ruas do Brasil. São Paulo: Carta Maior, 2013. p. 19- 26.

9. MARICATO E. Habitação e Cidade. 7. ed. São Paulo: Saraiva, 2010.

10. SANTOS M. Metrópole Corporativa Fragmentada: O caso de São Paulo.2. ed. São Paulo: Editora da Universidade de São Paulo, 2009.

11. SPOSITO MEB. Segregação socioespacial e centralidade urbana.

12. VASCONCELOS PA, CORRÊA RL, PINTAUDI SM. A cidade contemporânea: segregação espacial. São Paulo: Contexto, 2013

13. VILLAÇA F. Espaço Intra-Urbano no Brasil. 2. ed. São Paulo: Studio Nobel:, 2001. 